\title{
A Razão do Diagnóstico em Torno do Ideal Científico e a Ruptura Ética da Psicanálise
}

\author{
Márcia Cristina Maesso ${ }^{1}$ \\ Universidade de Brasília
}

\begin{abstract}
RESUMO - Esse artigo visa sustentar uma posição acerca do diagnóstico em referência à ética da psicanálise proposta por Lacan, que é orientada pelo real posto na praxis e não pelo ideal científico. Partindo dos conceitos estabelecidos na psicanálise, situa o diagnóstico como ato de mestria no discurso médico, formulando que o avesso desse discurso constitui a possibilidade de conceber o diagnóstico na psicanálise como semi-dizer do impasse experimentado na clínica.
\end{abstract}

Palavras-chave: diagnóstico, ética, clínica psicanalítica

\section{The Reason of Diagnosis Around the Scientific Ideal and Psychoanalysis Ethical Rupture}

\begin{abstract}
This article aims to sustain a position about the diagnosis in reference to the ethics of psychoanalysis proposed by Lacan, which is driven by real post in praxis and not by scientific ideal. Based on the concepts established in psychoanalysis, situated the diagnosis as an act of mastery in medical discourse, formulating that the reverse of this discourse is the possibility to devise the diagnosis in psychoanalysis as semi-say the deadlock experienced in the clinic.
\end{abstract}

Keywords: diagnosis, ethics, clinical psychoanalysis

A experiência clínica me incitou a investigar alguns problemas em torno dos fundamentos do diagnóstico na atualidade e a posição do psicanalista diante da função do diagnóstico na condução do tratamento. Procurei desdobrar essa temática na tese de doutorado, defendida em 2011 no Departamento de Psicologia Clínica da Universidade de São Paulo, tomando alguns conceitos psicanalíticos desenvolvidos por Lacan, entre os anos 1960 e 1970, envolvendo a ética, a clínica e a estrutura dos discursos, como referencial de leitura acerca do diagnóstico. O objetivo de retomar nesse artigo, alguns pontos que foram abordados no mencionado percurso, refere-se ao intuito de sustentar, no âmbito da ética da psicanálise, a escuta no tratamento dos sujeitos, cujos corpos manifestam dores crônicas de difícil explicação biológica, porque não correspondem a uma lesão visível. Esse fenômeno doloroso vem sendo diagnosticado na medicina como fibromialgia, assistido por meio da combinação de tratamentos farmacológicos e não farmacológicos, incluindo indicação de exercícios físicos variados e terapia cognitivo-comportamental.

Os estudos históricos apontam o quanto a dor está submetida aos códigos e normas sociais, que funcionam como reguladores dos modos de dizê-la, entre o que deve ser silenciado e o que deve transparecer. As "palavras da dor" contribuem para descrever sintomas e formular diagnósticos médicos, servindo às pesquisas científicas e

1 Endereço para correspondência: Campus Universitário Darcy Ribeiro, ICC, Ala Sul, Bloco A, Térreo, sala AT-030/7, Brasília, DF, Brasil, CEP: 70910-900.E-mail:maessom@unb.br ao estabelecimento da linguagem constituída em função do discurso médico (Rey, 2012, p. 22).

Na pesquisa teórica e clínica sobre corpo e dor, iniciada em 2012, em andamento no Departamento de Psicologia Clínica da UnB, acolhemos em tratamento, orientados pelos fundamentos da psicanálise, pessoas que receberam diagnóstico médico de síndrome fibromiálgica. Cabe salientar que, com essa pesquisa, visamos a oferecer uma escuta psicanalítica ao sujeito, e não tratar uma doença ou uma síndrome.

A fibromialgia é considerada uma categoria de doença, encontrada na Décima Revisão da Classificação Estatística Internacional de Doenças e Problemas Relacionados à Saúde (CID-10, 2007) sob o código M79.7 e, corresponde, segundo a definição do Colégio Americano de Reumatologia (ACR) a uma "síndrome dolorosa crônica não inflamatória". O diagnóstico da fibromialgia é pautado no exame clínico de palpação digital de 18 pontos de gatilho (tender points) difusos no corpo, dos quais 11 pontos devem ser localizados, observando a persistência da dor em período mínimo de três meses. (Hermann, et al., 2010; Kuahara, 2004).

A sumária contextualização acerca do diagnóstico da fibromialgia, permite considerar o problema da interpretação, por meio do discurso médico, dessa modalidade de manifestação da dor sem referente lesão no organismo; interpretação unicamente orientada pela busca desse referente que falta, excluindo a possibilidade de escutar o sujeito em seu dizer, ainda que ele o faça no limite da dor. Portanto, retomar o ideal científico que fundamenta o diagnóstico, 
importa para a clínica psicanalítica, principalmente diante das demandas de tratamento atreladas ao discurso médico.

\section{A colonização do termo diagnóstico}

É importante citar o estudo semântico do termo diagnóstico feito por Saurí (2001), porque ele indica o significado amplo do vocábulo como ato de conhecer, separar, discernir, implicando decisão, e também situa que na antiguidade o termo era utilizado num território extenso, além da medicina, pelos dramaturgos e filósofos. Ele mostra que, embora o termo diagnóstico ainda estenda-se a outros campos do conhecimento, como social, econômico, político, psicológico, etc., houve restrição e fixação da significação do termo ao campo médico, que pode ser traduzido como, "trabalho de conhecimento e reconhecimento de sinais, úteis para fixar alguma coisa" (p.11).

Nos dicionários de sinônimos da língua portuguesa, bem como nos dicionários especializados da medicina e de outros campos, o termo diagnóstico é compreendido como próprio do território médico, designando uma etapa do ato médico que consiste em identificar a doença por meio dos sinais ou sintomas. Nos dicionários de psicanálise, não consta o verbete diagnóstico, exceto o dicionário de Rycroft que aborda o termo, mas com a mesma conotação dos demais dicionários (Silvestre, 2008; Houaiss \& Villar, 2009; VandenBos, 2010).

Considerando o sentido amplo do ato de diagnosticar, enquanto ato de discernimento, de tratamento do real pelo simbólico, é possível situar que o diagnóstico não é prerrogativa da medicina, entretanto foi colonizado pelo campo médico como um ato que envolve aplicação de método específico para chegar à finalidade de conhecer a doença, de modo que esse significado ficou aderido ao termo. $\mathrm{O}$ verbete diagnóstico é considerado, na atualidade, como propriedade médica, designando a fase do ato médico de reconhecimento dos sinais e dos sintomas, que permitem elucidar a doença, em referência a determinado quadro, constituindo o ponto de partida que norteia o tratamento em função da cura.

Embora o método diagnóstico, concebido no campo médico, seja necessário para determinar o tratamento de várias afecções orgânicas, o mesmo método pode ser desastroso, quando aplicado sobre as formações do inconsciente usadas como meio de o sujeito dizer acerca de sua verdade. Esse é um dos problemas do diagnóstico que pretendemos apontar.

Acompanhamos o aumento da potência da ciência médica, nos avanços tecnológicos dos recursos diagnósticos, na busca do saber e da verdade, sobre várias categorias de transtornos e síndromes situados no conjunto das chamadas doenças mentais, caracterizadas pelas manifestações sintomáticas enigmáticas, que não podem ser explicadas pela inscrição de alguma lesão correspondente na estrutura do organismo, entretanto são compreendidas a partir da existência de problemas orgânicos funcionais. Não é nenhuma novidade, está bem exposto e sustentado pelos autores, que a psiquiatria na contemporaneidade inclui como um dos parâmetros de diagnóstico, a reação ao medicamento, a eficácia da ação das substâncias químicas na suspensão do sintoma, permitindo relacioná-lo a uma disfunção bioquímica do organismo. Desse modo, o diagnóstico passa a ser definido pelo tratamento aplicado (Zarrifian, 1989; Birman, 2001). Tampouco é novo o inventário do conhecimento sobre os transtornos mentais, considerado científico através do DSM (Manual Diagnóstico e Estatístico de Transtornos Mentais), composto pela Associação Psiquiátrica Americana, criado em 1952 e recentemente submetido ao processo de revisão com inclusão de diagnósticos de novas patologias mentais. A revisão agrega as inovações tecnológicas e a ampliação da farmacopéia na produção de recursos diagnósticos, permitindo amplificar a capacidade de leitura sobre as manifestações consideradas desviantes dos padrões determinados pela norma, portanto anormais. A versão lançada em maio de 2013 do DSM-5, indica pela utilização do numeral arábico no lugar do numeral romano, como era representado na versão anterior do DSMIV, o caráter não definitivo e inacabado do manual. Com essa nova numeração é possível garantir espaço para a inclusão de anexos (ou novas categorias diagnósticas?) antes da próxima revisão completa do manual, podendo vir a ser identificado como DSM-5.1, DSM-5.2, etc., enquanto o algarismo romano limita essa possibilidade (APA, 2013).

Esse manual instrumentaliza e universaliza a realização de um modelo específico de diagnóstico, orientado pela observação, pela comparação dos comportamentos e relatos do paciente sobre seu sofrimento, em relação aos quadros já estabelecidos, pela linguagem e saber médicos. O valor de mencionar alguns elementos que denotam o caráter inventivo, inacabado e não definitivo desse modelo de diagnóstico médico-psiquiátrico vigente nos nossos tempos, consiste em relativizar o peso de verdade que lhe é atribuído, bem como em propor que haja descolonização do termo diagnóstico do domínio metodológico da medicina, para que seja possível estendê-lo a outros campos e metodologias, considerando que existam problemas que requerem outros modos de investigação e tratamento. O discurso em torno do ideal científico, entretanto, propõe uma leitura que se opõe a essa, considerando o inacabamento do manual como uma questão temporária, com a certeza de que o avanço das pesquisas científicas possibilite responder no futuro, o que ainda não foi possível responder.

\section{O diagnóstico e o limite da simbolização}

Na clínica médica o sintoma é transformado em signo, na medida em que ele é um significante com significado definido, fixado e correlacionado ao repertório das doenças previamente catalogadas. Foucault discorreu sobre o sintoma na clínica médica como "doença em estado manifesto", um signo para ser lido, sendo assim, o médico detentor do conhecimento e da linguagem especializada é capaz de traduzi-lo como sinal indicativo de uma determinada doença. O corpo do doente é compreendido como um livro onde a doença escreve seus sinais. Por esse caminho, Foucault indicou a existência do ideal científico da medicina de chegar a uma "língua bem feita" que possibilite realizar uma "leitura exaustiva sem obscuridade ou resíduo", pela qual "todas as manifestações patológicas falariam uma linguagem clara e ordenada" e "todos os sintomas poderiam se tornar signos" (1998, pp. 104-107). 
O estudo de Foucault (1998), sobre o nascimento da clínica médica, retoma o caminho empreendido na busca do saber e da verdade sobre a doença, considerando que a verdade representada pelo nome (signo), é construída a priori pela observação, catalogação, classificação e descrição do fenômeno, bem como de sua repetição. Com essas ações é possível reunir elementos para formar um quadro de referência, que funcione como chave de linguagem, para reconhecer, interpretar e nomear o sintoma apresentado pelo paciente, como sinal correspondente à doença descrita nos códigos. Caso a doença seja desconhecida, poderá ser inserida em um novo quadro, pelo mesmo método composto pelas ações que corroboram a atividade da observação, em torno do visível. As técnicas usadas para conhecer o fenômeno patológico, são pautadas no método que pressupõe a sua visibilidade, da abertura de cadáveres aos exames de imagens, a sofisticação tecnológica aumentou as condições para torná-lo visível.

Tomemos a citação de Clavreul para contornarmos as consequências para o sujeito, do diagnóstico realizado no âmbito do discurso médico.

O que vai assinar sua entrada no discurso médico é a nomeação da doença, é o diagnóstico. Por aí, o médico mostra que aquilo de que o doente sofre tem seu lugar no sistema dos significantes que constitui o discurso médico. Esta nomeação, que é um aprisionamento, não comporta senão o aspecto negativo que toda categorização comporta. Ela é também, sobretudo para o doente, um ato que contribui para retirar sua angústia. Tudo que ele sentia, e que não podia ser relacionado com o que poderia ser interpretado a partir de seu saber sobre ele próprio, toda essa onda de sensações subjetivas penosas, dolorosas, angustiantes, freqüentemente culpabilizantes é retomada no discurso médico que afirma que um sentido pode ser encontrado para o que era anteriormente puro não-senso. (1983, p. 97).

A psicanálise trabalha com categorias diagnósticas fundamentadas pela inclusão da subjetividade, portanto, distintas das categorias constituídas pela ciência médica moderna, cujo método, por ser baseado na descrição, classificação e correlação dos fenômenos ao repertório existente nos códigos, pressupõe a exclusão da subjetividade, para, por essa via se sustentar. Por não excluir a subjetividade, a transferência é considerada na psicanálise como a via de acesso ou impedimento ao inconsciente, pela qual se torna possível construir um saber sobre a posição do sujeito em relação ao seu sofrimento e estabelecer a condução do tratamento (Freud, 1990/1912). A transferência é determinada pela função que tem na prática analítica, dirige o tratamento, é estabelecida como produto da situação analítica (embora também possa ocorrer fora dessa situação) porque a presença do analista equivale à manifestação do inconsciente (Lacan, 1964/1988).

Considerando com Clavreul, que o discurso médico comparece no diagnóstico, interpretando o sofrimento como doença, primeiro passo do conjunto de procedimentos que compõem o ato médico; a entrada do sujeito nesse discurso, através da nomeação diagnóstica, implica no seu apagamento, devido ao impedimento da articulação da cadeia de significantes no sentido de produzir uma verdade própria e singular. A cadeia de significantes se cristaliza no encontro de um significado, constituído pelo saber científico ao qual o médico está referido, saber que ocupa o lugar da verdade, positivando-a. Clavreul aproxima a entrada do doente no discurso médico, através do diagnóstico, à entrada da criança na linguagem por meio do discurso da mãe, sendo que ambos estão em condições semelhantes de desamparo, um que, fragilizado diante da doença, não pode obter a cura contando apenas consigo, e outro, pela prematuridade, não pode satisfazer as próprias necessidades vitais. Ambos apresentam uma demanda que é interpretada a partir do discurso do Outro, que está posicionado em relação a um saber (1983, p. 155). A aposta no diagnóstico referido ao saber do Outro, considerado como um saber potente, capaz de revelar a verdade sobre o sofrimento, alivia a angústia diante do desamparo, entretanto, produz alienação do sujeito e desapropriação de seu próprio saber.

Não raro, sofrimento e doença são confundidos no discurso médico, a depressão é um exemplo disso. O sofrimento humano se distingue da doença, na medida em que se relaciona com a fantasia, ou seja, com uma determinada posição do sujeito em relação ao objeto a em função de causa do desejo, conservando a parcela de insatisfação do desejo. A formulação do conceito de objeto a, por Lacan (1959-60/1997), designando que há um vazio irreparável, como um dos fundamentos do sofrimento humano, implica o sofrimento na própria constituição do sujeito. Por esse motivo, Clavreul (p. 156) declarou a importância de atribuir à composição do sofrimento, a esperança de reencontrar com o objeto a, como espera de algo ou alguém que possa assegurar o gozo do corpo.

A psicanálise propõe outro tratamento ao sofrimento e à formação do sintoma, diferenciando-o do signo, concebido para ser lido em referência a um sistema simbólico construído de antemão, para ofertar significados. Na psicanálise o sintoma deve ser interpretado, como designou Lacan (1966/1998), "na ordem do significante", indicando que o sintoma se relaciona à verdade do sujeito, na medida em que se articula em relação a outro significante. Citemos as palavras de Lacan, dada a clareza e importância do que ele enuncia, para a clínica psicanalítica:

Diferentemente do signo, da fumaça que não existe sem fogo, fogo que ela indica com o apelo, eventualmente, de que seja extinto, o sintoma só é interpretado na ordem do significante. O significante só tem sentido por sua relação com outro significante. É nessa articulação que reside a verdade do sintoma. O sintoma tinha um ar impreciso de representar alguma irrupção da verdade. A rigor, ele é verdade, por ser talhado na mesma madeira de que ela é feita, se afirmarmos materialisticamente que a verdade é aquilo que se instaura a partir da cadeia significante. (Lacan, 1966/1998, p. 235).

A partir dessa articulação entre sintoma, significante e irrupção de verdade, é possível considerar que a verdade sobre o sofrimento só pode ser dita por aquele que sofre, e como disse Lacan (1969-70/1992), "só se sustenta em um semi-dizer".

As articulações entre saber e verdade, propostas por Lacan nos seminários De um Outro ao outro (1968-1969/2008) e $O$ avesso da psicanálise (1969-1970/1992), fornecem elementos fundamentais para formular uma leitura a respeito do diagnóstico a partir do discurso da psicanálise. É importante para abordar a relação entre saber e verdade, compreender 
o matema que ele escreveu para designar o sujeito: $\mathrm{S} 1 \rightarrow$ $\mathrm{S} 2$, que se lê, o significante é aquilo que representa o sujeito para outro significante, designando o outro significante na conexão, o S2, como representante do saber. Saber que não é transparente, no qual o sujeito se apaga, operação nomeada com o termo fading, termo que pode ser traduzido por sumindo, conotando uma ação em curso. Lacan indicou o saber (S2) como função do inconsciente, considerando que toda a formação do inconsciente é uma interpretação. $\mathrm{O}$ sonho, para exemplificar, é em si mesmo uma interpretação, cujo significado na análise é o que menos importa, ou seja, não importa saber o que o sonho quer dizer, mas importa o deslizamento na cadeia significante, sobre "o que é que ao dizer isso quer" na formação do sonho, deslizamento que diz respeito, também, ao desejo realizado no sonho, não como satisfação, mas como formulação, interpretação do real.

No texto A ciência e a verdade, Lacan retoma a célebre frase de Freud "Wo Es war, soll Ich werden" traduzida por "Onde o Isso estava o Eu deverá advir", para tratar da divisão do sujeito entre saber e verdade, situando que no lugar do Isso, o sujeito do inconsciente surgirá. Ele formula que "a verdade fala sob o nome de inconsciente", que é "estruturado como uma linguagem", pois a verdade se coloca na superfície da fala, ela se encontra no próprio enunciado (1965/1998, p. 878).

Lacan propôs uma divisão da verdade dizendo que “ela só é acessível por um semi-dizer, que ela não pode ser inteiramente dita porque, para além de sua metade, não há nada a dizer". Ele aproveitou a ambiguidade da palavra francesa "pas" que significa ao mesmo tempo passo e negação, para apontar que o passo de sentido da cadeia significante (pas de sens) abriga a falta de sentido em si. Para Lacan, o sentido carrega o "peso do ser", e se ele propõe que o não-senso compõe metade do sujeito no encadeamento significante, meio de irrupção da verdade, compreende-se que há relação do que ele chamou de falta-a-ser, com o pasde-sens (passo de sentido sem sentido) no saber referente à verdade do sujeito que fala, falasser, através das formações do inconsciente, quais sejam, o sonho, o sintoma, o chiste, o ato falho. Algo da verdade escapa, é o impossível de apreender, assim como colocar sal na cauda de um pássaro, pois ele voa, como diz a metáfora de Lacan (1969-70/1992, pp. 49-55).

Com essas formulações, Lacan (1969-70/1992) evidenciou a inacessibilidade do real e o limite da simbolização, de onde depreendemos que há também um limite para o diagnóstico. O diagnóstico é um meio de simbolização do real, mas não de todo o real. O limite da simbolização, na atividade diagnóstica como sentido ofertado pelo Outro, é importante para conservar o intervalo onde o sujeito se articula em relação ao sentido do desejo e constitui o seu saber.

\section{Como ler o que não se escreve?}

A leitura psicanalítica feita por Clavreul (1983), sobre o discurso médico, foi fundamentada nas formulações de Lacan (1969-1970) realizadas ao longo do seminário $O$ avesso da psicanálise, a respeito dos quatro discursos: do mestre, da histérica, universitário e psicanalítico. Tomemos como referência essa leitura, porque aproxima o discurso médico ao discurso do mestre, para considerar a razão do diagnóstico em torno do ideal científico, e as consequências desse determinado modo de diagnosticar, para o sujeito.

Para fazer esse caminho, cabe relembrar que cada discurso elaborado por Lacan é composto por um conjunto de quatro elementos (S1, S2, \$, a), sendo que cada elemento é definido a partir da relação com outros dois elementos. O sujeito é dividido (\$) em dupla relação: uma relação se estabelece pela cadeia significante $(\mathrm{S} 1 \rightarrow \mathrm{S} 2)$ onde o sujeito se representa em apagamento, ou seja, apagamento de um gozo absoluto; a outra relação se estabelece entre o sujeito e o objeto (a), permitindo estruturar a fantasia. O significante mestre (S1) articula-se ao saber (S2) para representar o sujeito (\$), mas o sujeito (\$) não se inscreve em um discurso sem articular-se ao objeto a. Os elementos ou as letras do discurso também dependem do lugar (agente, trabalho, produção, verdade) em que estão posicionados para constituir um determinado discurso (Clavreul, 1983; Lacan, 1969-1970/1992). Em resumo, cada discurso estrutura um modo distinto de relação do sujeito com o significante e o objeto a.

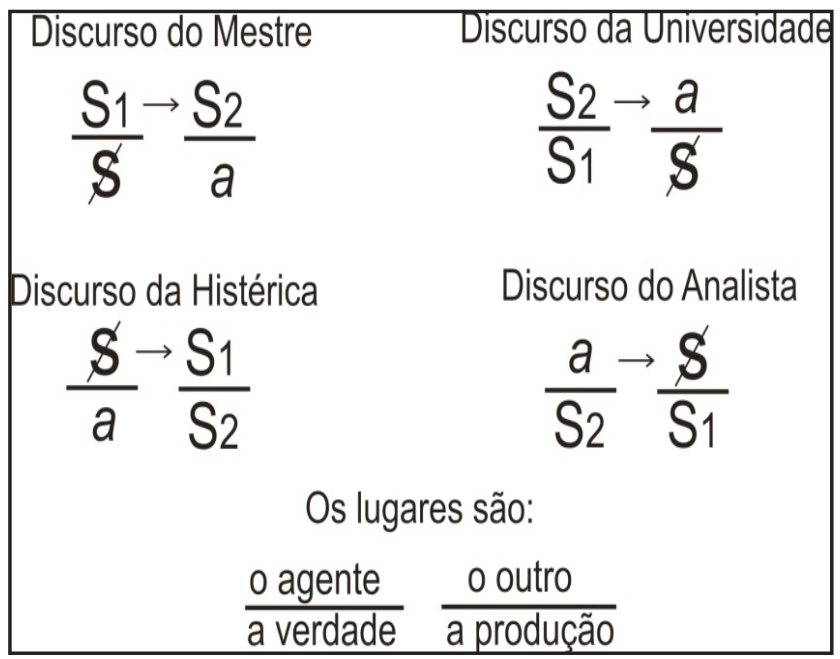

Figura 1. Escrita na forma matemática dos quatro discursos formulados por Lacan (1969/70/1992, p. 65).

Visando considerar as consequências para o sujeito, do ato diagnóstico operado no âmbito do discurso médico, e o avesso dessa operação, trataremos do discurso do mestre e do discurso do psicanalista, no que eles permitem contornar essa questão.

Das leituras possíveis a partir do discurso do mestre, destaquemos que a fórmula desse discurso (Figura 1) se escreve colocando o \$ sob a barra, como indicação da ausência do sujeito. Isso mostra que ele é o único discurso que impossibilita a articulação da fantasia, porque a relação do sujeito dividido (\$) com o objeto (a) causa do desejo, não é contemplada, ou seja, "o discurso do mestre exclui a fantasia” (Lacan, 1969-1970/1992, p. 101).

Aproximando a estrutura do discurso médico à estrutura do discurso do mestre, Clavreul indica que "a etapa do diagnóstico é um ato de mestria". Por meio do ato diagnóstico, os indícios clínicos ou paraclínicos, apresentados pelos pacientes, são articulados na cadeia de significantes constituídos pelo discurso médico, de onde se extrai uma 
significação correspondente a uma doença ou síndrome. A possibilidade do ato de mestria, no diagnóstico, consiste não apenas pelo saber já constituído, o repertório criado, mas pelo método que possibilita a criação de novo repertório, com a inclusão de novas categorias. Nesse discurso a subjetividade é excluída para garantir a objetividade científica.

A exclusão da subjetividade no discurso médico pode ser lida com a exclusão da fantasia no discurso do mestre, mas ao aproximar esses discursos, Clavreul também considerou que o produto alocado no lugar do objeto a (objeto causa do desejo em ausência e mais-de-gozar em presença) seja a doença. A presença do objeto, sua positividade na doença, é geradora de gozo: "O objeto "a" desaparece como causa do desejo reaparecendo como achado no discurso" (p. 170).

Partindo da aproximação desses discursos, torna-se possível situar o diagnóstico dos transtornos mentais, referido ao discurso médico, em correlação ao ato de mestria, assim, utilizamos a escrita lacaniana do discurso do mestre para representá-lo.

Colocando no lugar do $\mathrm{S} 1$, o ato diagnóstico que inclui a nomeação da doença ou síndrome, e no lugar do S2 o prognóstico, como demonstramos na Figura 2., podemos circunscrever, com essa pequena alteração na fórmula do discurso do mestre, uma relação que provoca o desaparecimento do sujeito pela identificação ao nome da doença, nome a partir do qual passa a reconhecer o sentido do seu sintoma.

$\mathrm{O}$ ato diagnóstico é colocado no lugar do agente, como significante mestre (S1), para formular que o princípio dos procedimentos médicos para chegar à verdade da doença,

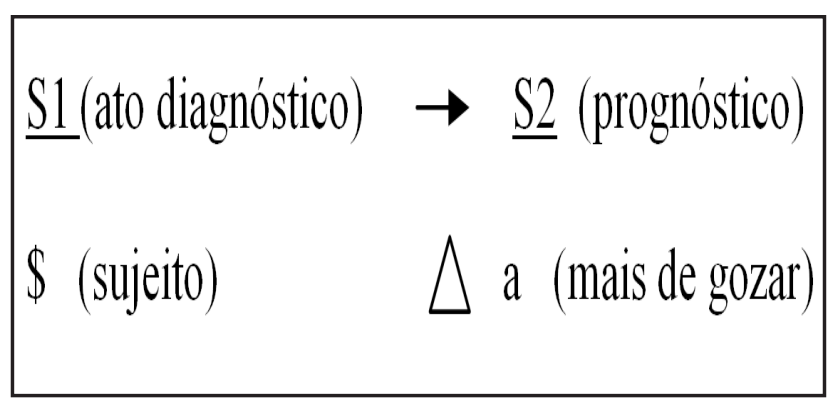

Figura 2. A escrita do diagnóstico referido ao discurso do mestre.

corrobora um ato de mestria, o passo que marca a entrada do sujeito no discurso médico. A nomeação diagnóstica é a consolidação do saber sobre a doença, ao qual se chega a partir da investigação clínica, pela correlação das manifestações enigmáticas para o paciente, da queixa por ele relatada, ao saber já constituído da doença; saber que nos nossos tempos, encontra-se materializado no manual de diagnóstico das doenças mentais (DSM). O diagnóstico atribui ao significante a posição de significado, propondo uma leitura pré-determinada pela linguagem especializada criada no campo médico sobre as manifestações sintomáticas do sujeito, que passam a ser designadas como manifestação da doença.

O sentido do diagnóstico é o prognóstico, situado como saber (S2) preditivo. Uma realidade com peso de verdade é criada pelo diagnóstico e articulada ao prognóstico, produzindo modificação da relação entre o sujeito e o seu sintoma. Sob o efeito do ato diagnóstico, o sujeito dificilmente poderá responsabilizar-se pela tarefa de decifrar o sintoma na ordem do significante, porque o sintoma passa a ser dominado pelo significado, oriundo do saber médico.

O diagnóstico de uma síndrome ou de uma doença caracterizada como mental é proferido para designar algo que ocorre no território psíquico, como meio de explicar e conhecer, suprimindo o que de modo geral é gerador (gera a dor) de perturbações para o sujeito; em outras palavras, o diagnóstico trata as formações subjetivas como sinais de doença. Sobretudo, a nomeação diagnóstica como significado, no lugar de agente, de significante mestre (S1), tem como consequência, o disparo de uma trajetória de repetição e gozo ordenados pelo discurso pretensamente científico.

Lacan situa o objeto a como mais-de-gozar, estabelecendo relação à mais-valia marxista, não simplesmente a partir de uma analogia, mas tratando de colocar como mesma coisa, dizendo que "a relação do mais-de-gozar com a mais-valia gira em torno da função do objeto a". O autor indica que na articulação entre os significantes, por meio da repetição que visa ao gozo, ocorre perda de gozo, donde aparece a função do objeto perdido, por ele chamado objeto a. Como a busca pelo gozo do objeto é fracassada, o mais-de-gozar efetuaria a sua função de compensar a perda de gozo. Lacan aponta que Marx denuncia a espoliação de gozo pela mais-valia, e considera que é a partir dessa perda que decorre a busca de mais-de-gozar, o que ele ilustra por meio da sociedade de consumidores, atrás dos objetos produzidos pela indústria, no capitalismo (1969-1970/1992, pp. 44-45).

O mais-de-gozar (objeto a), colocado nessa referência diagnóstica (proposta pela medicina) no lugar da produção (abaixo e à direita no esquema da Figura 2.), pode situar o ganho de (re)conhecimento obtido pela ciência por duas vias: a via que comprova as hipóteses e saberes científicos pelo diagnóstico, baseado na correspondência entre sintoma e signo da doença; e a via econômica, pela venda dos medicamentos que agem na suspensão dos sintomas, gerando lucro e aumento do capital das indústrias farmacêuticas.

Do ponto de vista do paciente, o mais-de-gozar poderia relacionar-se ao alívio de ter seu enigmático malestar traduzido em sintoma (re)conhecido pelo Outro, representado no saber médico; e pela promessa de cura que o tratamento medicamentoso instaura. Além disso, o efeito do medicamento psicotrópico conserva a função do objeto a, pelo gozo do consumo de substâncias químicas das quais se espera obtenção de prazer, pela suspensão do sintoma.

A exclusão da subjetividade no diagnóstico fundamentado pelo discurso médico relaciona-se à impossibilidade da articulação da fantasia como no discurso do mestre, mas refere-se também à deontologia à qual os médicos estão submetidos, tendo por princípio, garantir a razão científica. Numa direção contrária, a clínica psicanalítica iniciou-se pela transferência amorosa, pelo acolhimento da encenação da fantasia, atrelando a função do psicanalista em relação a uma ética, distinta do código de conduta, cujos princípios são fundamentais nessa discussão acerca do diagnóstico.

No seminário intitulado A ética da psicanálise, o caminho que Lacan (1959-1960/1997) percorreu, tratou da retirada 
da discussão sobre a ética que comumente incide sobre o domínio do ideal, passando a orientá-la na relação do homem ao real, que, como já dissemos anteriormente, consiste em ser inacessível e marca o limite do simbólico. Tomando como referência o conceito freudiano de das Ding, ou a Coisa forado-significado, que se desdobra no conceito de objeto desde sempre perdido, Lacan situou que a ética na psicanálise se regula em função do princípio do prazer, que funciona em alternância com o desprazer, conservando o objeto como perdido e o encontro de das Ding como impossível. Em torno da falta, Lacan fundamentou a ética do desejo e considerou que a civilização se organiza de diferentes modos, a partir do vazio constituído pela falta do objeto: contornando-o pela arte; evitando-o pela religião; ou rejeitando-o pela ciência. Diante do real, Lacan (1959-1960/1997) concebeu que a posição ética do psicanalista não seja a de solucionar o sofrimento do sujeito, correspondente ao vazio demarcado pela impossibilidade de das Ding e à complexa relação com o objeto perdido; mas seja a de sustentar a transferência, posicionando-se como testemunha do inconsciente, conservando o intervalo que viabiliza a articulação do sujeito, para que lhe seja possível formular sobre seu desejo.

No discurso do psicanalista (Figura 1.) cujo agente é o objeto a causa do desejo, o sujeito é impelido a articular-se na cadeia de significantes, gerando no lugar da produção o significante mestre (S1) como traço do sujeito, e no lugar da verdade o saber (S2) como semi-dizer.

$\mathrm{O}$ discurso do analista situa-se em sentido oposto ao discurso do mestre, portanto também ao discurso médico e ao método diagnóstico como ato de mestria. Entretanto, o diagnóstico em sua ampla acepção de discernimento, de tomada de posição, tem função importante na psicanálise, de separar o momento em que acontece o evento clínico e o momento de formulá-lo a partir dos conceitos estabelecidos nos limites de seu campo, mesmo que os limites correspondam a uma abertura ao sentido. É importante também na separação das subjetividades. O diagnóstico na psicanálise é o avesso do diagnóstico médico em relação ao método, ao momento de sua realização e sua incidência na direção do tratamento. Os casos que foram escritos por Freud (1990/1893-1895), demonstram que o diagnóstico na acepção médica do termo, não é imprescindível para que o tratamento aconteça e tampouco é o que determina sua direção. Enquanto o diagnóstico médico passa ao prognóstico para orientar o tratamento do início ao fim, na psicanálise o diagnóstico não se impõe como condição de seu início nem determina o fim.

Nos Estudos sobre a histeria (1990/1893-1895) realizado no momento inicial da psicanálise, Freud considerou que o preparo para diagnosticar obtido em sua formação médica, não lhe valia diante do que lhe era imposto na práxis clínica, e que, estranhamente era convocado a escrever os relatos de caso como contos, semelhantes aos dos escritores imaginativos, deixando faltar a marca pela qual a seriedade científica poderia ser reconhecida. Entretanto, constatou que devido à natureza do assunto, esse era o melhor caminho para chegar a alguma compreensão sobre o sofrimento dos pacientes.

Com seu artigo Escritores criativos e devaneios (1990/1908), Freud aproximou a atividade de brincar exercida pela criança, da ação do escritor na criação poética, e formulou que "a antítese de brincar não é o que é sério, mas o que é real". Desse modo, compreendemos que Freud apontava a uma função do psicanalista, à qual ele era transferencialmente impelido a exercer, a partir do real que surgia em sua clínica. Aceitando ser conduzido pelas interpelações que a atividade clínica produzia, Freud realizou a investigação teórica, diagnóstica, dentro da ética psicanalítica, sem pretensão de proferir a última palavra e tampouco de considerar como doença, as formações do inconsciente.

Desde o princípio de suas formulações, sobretudo com sua práxis, Freud demonstrou que o diagnóstico na psicanálise se fundamenta na escrita do caso feita pelo psicanalista, posicionado na relação transferencial. A escrita do caso clínico, como caminho para diagnosticar na psicanálise, no sentido amplo de discernimento, implica numa temporalidade posterior ao momento da experiência clínica, não possibilita a antecipação dos efeitos de uma determinada intervenção, entretanto, permite ao analista, situar-se advertidamente na relação transferencial, em relação ao saber e verdade que advém do sujeito.

\section{Considerações Finais}

Buscamos abordar os fundamentos do diagnóstico que impera na atualidade, utilizando a estrutura do discurso do mestre proposta por Lacan, como referencial de leitura do ato diagnóstico correspondente ao discurso médico, para situar as consequências desse ato, na relação do sujeito quanto ao seu sintoma. Na contramão do diagnóstico operado de acordo com o discurso médico, buscamos formular que as articulações entre saber e verdade acerca do sofrimento podem ser viabilizadas, através do discurso do psicanalista, pelo próprio sujeito, assim o fundamento do diagnóstico na psicanálise, situa-se no ato de nomear em referência à língua singular daquele que sofre. Também consideramos que o sofrimento diz respeito ao encontro falhado com o objeto instituído na fantasia como causa do desejo, ou maisde-gozar, conservando um resto impossível de satisfazer, de modo que, no campo da psicanálise, concebe-se uma distinção entre o sofrimento manifesto no sintoma e a doença.

Visamos sustentar que a posição do psicanalista, diante da função do diagnóstico, na condução do tratamento, respeita a ética norteada pelo real da praxis, rompendo com o ideal científico. Portanto, o limite da simbolização, na atividade diagnóstica, torna-se necessário para conservar o intervalo onde o sujeito se articula em relação ao desejo. Formulando com outras palavras, quando o saber teórico ou científico não é sobreposto, como interpretação do modo do sujeito dizer sobre seu sofrimento, há abertura para a inclusão do sujeito na produção de sentido (pas de sens) acerca de suas manifestações sintomáticas, e na implicação quanto ao tratamento. A posição do psicanalista em relação ao diagnóstico pode ser lida na fórmula do discurso do analista (Figura 1.), que é o avesso do discurso do mestre, onde os elementos estão escritos no pólo oposto ao desse último. O discurso do psicanalista incita o trabalho do sujeito (\$), situando no lugar do agente o objeto (a) causa do desejo, o significante mestre (S1) sob a barra, indicando uma perda e 
o saber (S2) no lugar da verdade, também localizado sob a barra, como verdade não toda, sendo apreendida pela metade, pois dela apenas é possível semi-dizer.

Embora, no decurso do artigo, a ênfase tenha recaído sobre o diagnóstico médico-psiquiátrico exercido na saúde mental e de seus efeitos para o sujeito, também é possível considerar as consequências para o sujeito do diagnóstico médico da dor crônica, quando desconectando-a da subjetividade para tomá-la exclusivamente como sinal de doença no organismo, contribui para desincumbir o sujeito de sua responsabilidade na investigação das manifestações da dor no seu corpo e sua função em relação a uma determinada posição subjetiva assumida e sustentada inconscientemente.

O caminho proposto nesse trabalho leva a reconhecer que, tanto a atividade de escrita de caso exercida por Freud, quanto a escrita das fórmulas matemáticas ou os matemas concebidos por Lacan, são meios de tocar o real, sob a advertência de que não é possível esgotá-lo. Por esse motivo, consideramos essas modalidades de escrita na composição de um instrumento metodológico fecundo para uma diagnóstica referida à ética psicanalítica.

\section{Referências}

APA (2013). Recuperado de http://www.dsm5.org/about/Pages/ faq.aspx \#8

Birman, J. (2001). Mal-estar na atualidade: a psicanálise e as novas formas de subjetivação (3a. ed.). Rio de Janeiro: Civilização Brasileira.

CID-10 (2007). Recuperado de www.google.com.br/search?hl=pt$\mathrm{BR} \& \mathrm{tbo}=\mathrm{p} \& \mathrm{tbm}=\mathrm{bks} \& \mathrm{q}=\mathrm{isbn}: 8531403855$

Clavreul, J. (1983). A ordem médica: poder e impotência do discurso médico. São Paulo: Editora Brasiliense.

Foucault, M. (1998). O nascimento da clínica (5a ed.). Rio de Janeiro: Forense Universitária.

Freud, S. (1990). Estudos sobre a histeria. In J. Strachey, (Ed. \& Trans.), Obras completas (Vol. 2, pp.152-189). Rio de Janeiro: Imago. (Trabalho original publicado em 1895)

Freud, S. (1990). Escritores criativos e devaneio. In J. Strachey, (Ed. \& Trans.), Obras completas (Vol. 9, pp.147-149). Rio de Janeiro: Imago. (Trabalho original publicado em 1908 [1907])
Freud, S. (1990). A dinâmica da transferência. In J. Strachey (Ed. \& Trans.), Obras completas (Vol. 12, pp.131-143). Rio de Janeiro: Imago. (Trabalho original publicado em 1912)

Hermann, R. E., Paiva, E. S., Helfensein Junior, M., Pollak, D. F., Martinez, J. E., Provenza J. R., . . Fonseca, M. C. M. (2010). Consenso brasileiro do tratamento da fibromialgia. Revista Brasileira de Reumatologia: Órgão oficial da Sociedade Brasileira de Reumatologia, 50(1), 56-66.

Houaiss, A. \& Villar, M. S. (2009). Dicionário Houaiss da lingua portuguesa. Rio de Janeiro: Objetiva.

Kuahara, M.V. (2004). Fibromialgia: A percepção da doença pela mulher. Uma investigação através do método qualitativo (Unpublished Doctoral dissertation). Programa de PósGraduação em Reumatologia, Escola Paulista de Medicina, Universidade Federal de São Paulo, São Paulo.

Lacan, J. (1997). O seminário: livro 7: a ética da psicanálise. Rio de Janeiro: Jorge Zahar. (Trabalho original publicado em 1959/1960)

Lacan, J. (1988). O seminário: livro 11: os quatro conceitos fundamentais da psicanálise. Rio de Janeiro: Jorge Zahar. (Trabalho original publicado em 1964)

Lacan, J. (1998). A ciência e a verdade. Escritos. Rio de Janeiro: Jorge Zahar. (Trabalho original publicado em 1965)

Lacan, J. (1998). Do sujeito enfim em questão. Escritos. Rio de Janeiro: Jorge Zahar. (Trabalho original publicado em 1998)

Lacan, J. (2008). O seminário: livro 16: de um Outro ao outro. Rio de Janeiro: Jorge Zahar. (Trabalho original publicado em 1968/1969)

Lacan, J. (1992). O seminário: livro 17: o avesso da psicanálise. Rio de Janeiro: Jorge Zahar. (Trabalho original publicado em 1969/1970)

Rey, R. (2012). História da dor (C. Gambini, Trad.). São Paulo: Escuta.

Saurí, J. J. (2001). O que é diagnosticar em psiquiatria? São Paulo: Escuta.

Silvestre, M. L. C. (2008). Investigação sobre o diagnóstico: um diálogo possível entre a psicanálise e a medicina (Unpublished master's thesis). Instituto de Psicologia, Universidade de São Paulo, São Paulo.

VandenBos, G. R. (Ed.). (2010). Dicionário de psicologia da APA. Porto Alegre: Artmed.

Zarrifian, E. (1989). Um diagnóstico em psiquiatria: para quê? In J. Lacan (Ed.), A querela dos diagnósticos (pp. 45-51). Rio de Janeiro: Jorge Zahar. 